\title{
(1) canen \\ Usefulness of multimodality cardiac imaging in a patient with ST elevation myocardial infarction caused by two giant coronary artery aneurysms
}

\author{
Satoshi Hayashida, ${ }^{01}$ Tsukasa Yagi, ${ }^{2}$ Yasuyuki Suzuki, ${ }^{2}$ Eizo Tachibana ${ }^{1}$
}

${ }^{1}$ Cardiology, Kawaguchi Municipal Medical Center, Kawaguchi, Japan

${ }^{2}$ Cardiology, Nihon University, Tokyo, Japan

\section{Correspondence to} Dr Satoshi Hayashida, satoshi.hayashida1@gmail.com

Accepted 26 June 2019

Check for updates

(c) BMJ Publishing Group Limited 2019. Re-use permitted under CC BY-NC. No commercial re-use. See rights and permissions. Published by BMJ.

To cite: Hayashida S, Yagi T, Suzuki Y, et al. BMJ Case Rep 2019:12:e229995. doi:10.1136/bcr-2019229995

\section{SUMMARY}

Coronary artery aneurysm (CAA) is a rare cause of myocardial infarction. However, only a few studies have investigated this aspect. An 84-year-old woman with a history of hypertension presented with nausea. showed ST elevation in the inferior leads, and coronary angiography revealed two giant CAAs in the right coronary artery. Percutaneous coronary intervention was difficult because of risk of CAA rupture. Thus, these aneurysms were further evaluated using multimodality cardiac imaging to determine the treatment. MRI using late gadolinium enhancement revealed structural features of the aneurysms and the viability of the myocardium. Only antithrombotic medication was administered on the basis of the results of the multimodality cardiac imaging. Here, we report a rare case of a patient diagnosed with ST elevation myocardial infarction caused by thrombosis in giant CAAs using multimodality cardiac imaging, particularly MRI.

\section{BACKGROUND}

Ischaemic heart disease is one of the most common causes of death, and its frequency is increasing worldwide. The mortality of patients with ST elevation myocardial infarction (STEMI) is influenced by many factors, such as advanced age, Killip class and delayed treatment. ${ }^{1-3}$ Guidelines for the management of STEMI emphasise that a patient with STEMI should be administered reperfusion therapy as soon as possible. ${ }^{14}$ Unfortunately, difficulty in performing primary percutaneous coronary intervention (PCI) sometimes delays time to reperfusion. A rare reason for this is the presence of Coronary artery aneurysm (CAA) in the culprit artery of infarction. However, because of the low incidence of CAA, it is detected only approximately $1.65 \%$ by coronary angiography (CAG). Moreover, studies on CAA are limited, and the treatment for patients with STEMI caused by CAA has not been established. ${ }^{5}$

\section{CASE PRESENTATION}

An 84-year-old woman presented to her family doctor with nausea that persisted for 3 days. Her medical history included hypertension. There was no family history of cardiovascular disease. Because ECG showed ST elevation in the inferior leads, she was referred to our hospital with a diagnosis of STEMI. On arrival, she was asymptomatic. Vital signs and physical examination showed untoward features. ECG revealed ST elevation; thus, CAG was performed.

\section{INVESTIGATIONS}

On admission, blood examination revealed the levels of the following: creatine kinase, $285 \mathrm{IU} / \mathrm{L}$ and troponinT, $1.590 \mathrm{ng} / \mathrm{mL}$. CAG revealed two giant CAAs in the right coronary artery (RCA) (figure 1). Distal end of these aneurysms was not defined; there was stenosis on the exit side of these aneurysms. PCI was difficult because of the risk of CAA rupture. Therefore, the following cardiac imaging examinations were performed to evaluate these aneurysms: transthoracic echocardiography, myocardial perfusion single photon emission computed tomography (SPECT), CT and MRI.

Two large masses were observed near the aorta and in the right atrioventricular groove area by transthoracic echocardiography. Each mass was approximately $40 \times 40 \mathrm{~mm}$. Thrombosis was identified in the aneurysms.

Adenosine stress thallium-201 myocardial perfusion SPECT showed fixed defect in the inferior wall, and this result indicated myocardial infarction (MI) in the RCA territory.

Multidetector CT and volume rendering showed two giant CAAs followed by the RCA, and multiplanar reconstruction showed two giant CAAs and some thrombosis in one of the aneurysms (figure 2).

MRI revealed the shape of the CAAs and the viability of the myocardium (figure 3 ). Cine MRI revealed myocardial wall thinning and akinesis in the inferior wall, and late gadolinium enhancement revealed inferior myocardial scar with $>50 \%$ transmurality. Cine MRI also showed turbulent flow in the CAA.

Therefore, these imaging modalities indicated that infarction of the inferior wall was caused by thromboses which were a consequence of turbulent flow in CAAs.

\section{TREATMENT}

Surgery was presented as a treatment option because of the risk of CAA rupture. Because she refused to undergo surgery, she was administered antiplatelet and anticoagulant agents: aspirin $100 \mathrm{mg} /$ day and warfarin. 


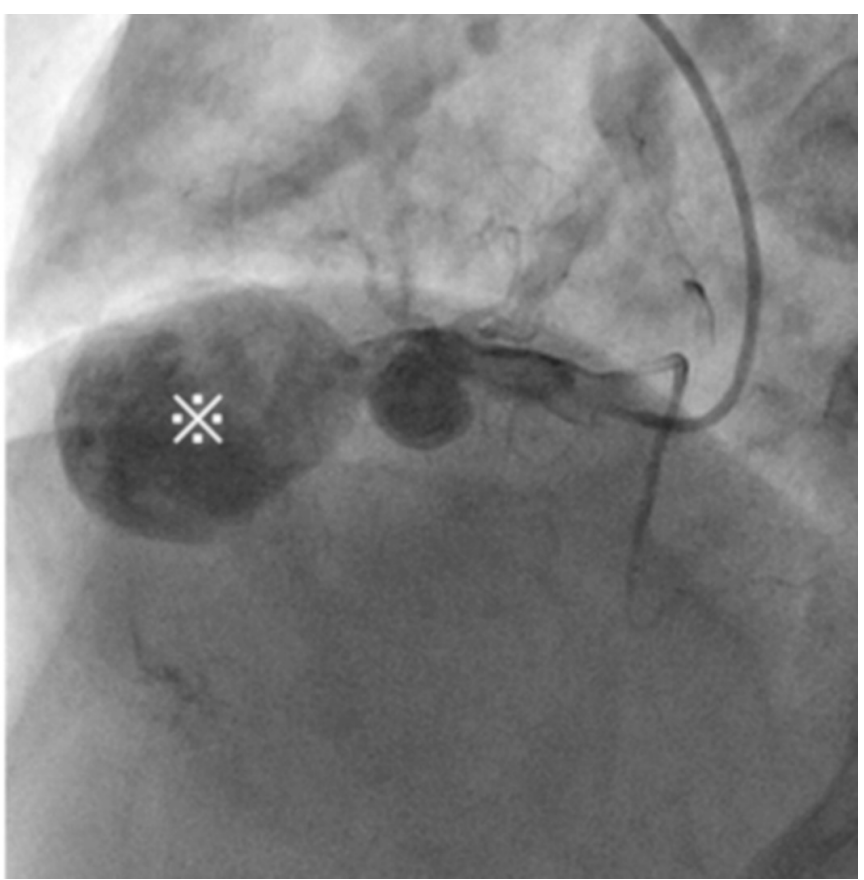

Figure 1 Coronary angiography revealing giant aneurysm $(※)$ in right coronary artery.

\section{OUTCOME AND FOLLOW-UP}

At 22 months from onset, she died of a sudden cardiac arrest. Her CT on autopsy showed massive pericardial effusion. The suggested direct cause of death was cardiac tamponade because of CAA rupture.

\section{DISCUSSION}

In Japan, the peak age of female patients with acute myocardial infarction (AMI) is 80-89 years. ${ }^{2}$ Elderly individuals with MI exhibit various complications, with CAA being a rare complication. CAA is defined as local dilatations in the coronary that are 1.5 -fold greater than normal adjacent segments. ${ }^{6}$ Because patients with CAA seldom have subjective symptoms, they are almost accidentally diagnosed. A study reported that the incidence of CAA was approximately $0.2 \%-2.6 \%$ diagnosed by CAG and was most common in the RCA. ${ }^{78}$ Moreover, approximately $50 \%$ of CAA are caused by atherosclerosis, followed by congenital disease (20\%-30\%). Kawasaki disease, autoimmune disorder and injury also cause CAA. ${ }^{9}$ However, the specific mechanisms that drive the formation of CAA remain unclear because of its rarity. $^{6}$

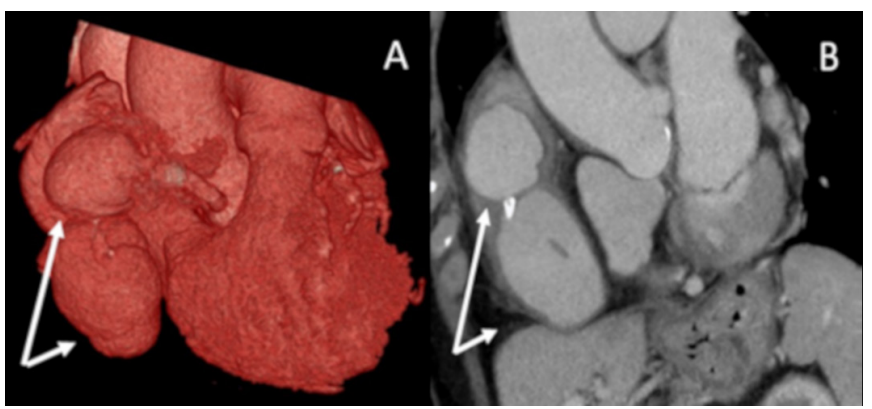

Figure 2 Multidetector-row CT. (A) Volume rendering imaging, (B) multiplaner reconstruction $(\rightarrow)$ show coronary artery aneurysms.

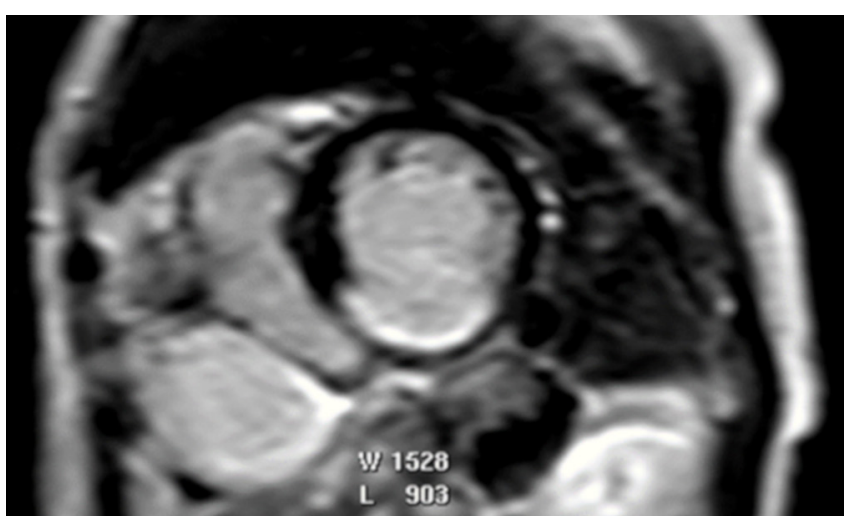

Figure $3 \mathrm{MRI}$ revealing wall thinning and late gadolinium enhancement in the inferior wall.

The treatment for patients with STEMI caused by CAA has not been established. A previous study reported that MI was caused by CAA in an elderly patient who underwent PCI by covered stent implantation. ${ }^{10}$ In contrast, Yanik et al said that a conservative approach is recommended in asymptomatic patients with MI because it is difficult to cross the thrombosed outlet of the CAA and there is a risk of rupture by intervention wire. ${ }^{11}$ In addition, a few studies have reported that anticoagulation therapy reduces the risk of MI and sudden cardiac arrest in patients with CAA. ${ }^{12} 13$ Furthermore, another study recommends surgical treatment for all CAAs that are $>3 \mathrm{~cm}$ because of the risk of rupture. ${ }^{14}$

Generally, CAA is diagnosed by transthoracic echocardiography, CAG and CT. A few reports have mentioned the use of MRI for diagnosing CAA. ${ }^{15} 16$ Particularly, cine MRI can be used to image cardiac motion, including CAA, turbulence of blood flow and myocardial asynergy by aneurysm. Late gadolinium enhancement MRI (LGE-MRI) is also useful for determining invasion depth of subendocardial infarction. Choi et al reported the diagnostic capabilities of LGE-MRI in patients with AMI who had an onset within 1 week. ${ }^{17}$ Kitagawa reported the transmural extent of infarcted myocardium, and $>50 \%$ had evaluated the absence of myocardium viability. ${ }^{18}$

In the presented case, PCI was difficult because of the risk of CAA rupture by intervention wire, and she was asymptomatic during CAG. Multimodality images revealed that the thrombosis in CAAs has resulted in coronary artery stenosis. Furthermore, LGE revealed inferior myocardial scar with $>50 \%$ transmurality. Surgery was recommended due to the risk of CAA rupture; however, the patient refused to undergo surgery. Hence, she was administered medication. Consequently, she survived for only 22 months from onset. Transthoracic echocardiography, CT

\section{Learning points}

- Treatment of coronary aneurysm is different in each case and depends on size of the aneurysm or condition of patients.

- This is a rare case of a patient diagnosed with ST elevation myocardial infarction caused by thrombosis in giant coronary aneurysms using multimodality cardiac imaging, particularly MRI.

- Knowing the shape of the coronary aneurysms and the condition of the myocardium using various imaging techniques can help in determining the best treatment, considering the background of patients. 
and MRI were used for determining the condition of CAA. In this case, multimodality imaging, including MRI, contributed in making the treatment decision. Moreover, MRI is a non-invasive modality without the risk of radiation exposure and can help in determining the characteristics of the myocardium and anatomical cardiovascular structures.

In conclusion, multimodality imaging, including MRI, are useful in the diagnosis of MI caused by CAA. Further studies on CAA are essential to decrease mortality by CAA and establish the guidelines for treatment.

Contributors SH and YS designed the manuscript, and wrote the initial draft. SH, YS and TY contributed to analysis and interpretation of data. YS and TY assisted in the preparation of the manuscript. ET have contributed to data collection and interpretation, and critically reviewed the manuscript. All authors approved the final version of the manuscript, and agreed to be accountable for all aspects of the work in ensuring that questions related to the accuracy or integrity of any part of the work are appropriately investigated and resolved.

Funding The authors have not declared a specific grant for this research from any funding agency in the public, commercial or not-for-profit sectors.

\section{Competing interests None declared.}

Patient consent for publication Next of kin consent obtained.

Provenance and peer review Not commissioned; externally peer reviewed.

Open access This is an open access article distributed in accordance with the Creative Commons Attribution Non Commercial (CC BY-NC 4.0) license, which permits others to distribute, remix, adapt, build upon this work non-commercially, and license their derivative works on different terms, provided the original work is properly cited and the use is non-commercial. See: http://creativecommons.org/ licenses/by-nc/4.0/

\section{REFERENCES}

1 Ibanez B, James S, Agewall S, et al. 2017 ESC Guidelines for the management of acute myocardial infarction in patients presenting with ST-segment elevation: The Task Force for the management of acute myocardial infarction in patients presenting with ST-segment elevation of the European Society of Cardiology (ESC). Eur Heart J 2018;39:119-77.
2 Yasuda S, Nakao K, Nishimura K, et al. The Current Status of Cardiovascular Medicine in Japan - Analysis of a Large Number of Health Records From a Nationwide ClaimBased Database, JROAD-DPC. Circ J 2016;80:2327-35.

3 Ueki Y, Mohri M, Matoba T, et al. Characteristics and Predictors of Mortality in Patients With Cardiovascular Shock in Japan - Results From the Japanese Circulation Society Cardiovascular Shock Registry. Circ J 2016:80:852-9.

4 O'Gara PT, Kushner FG, Ascheim DD, et al. 2013 ACCF/AHA guideline for the management of ST-elevation myocardial infarction: a report of the American College of Cardiology Foundation/American Heart Association Task Force on Practice Guidelines. Circulation 2013;127:e362-425.

5 Cohen P, O'Gara PT. Coronary artery aneurysms: a review of the natural history, pathophysiology, and management. Cardiol Rev 2008;16:301-4.

6 Abou Sherif S, Ozden Tok O, Taşköylü Ö, et al. Coronary Artery Aneurysms: A Review of the Epidemiology, Pathophysiology, Diagnosis, and Treatment. Front Cardiovasc Med 2017:4:24

7 Tunick PA, Slater J, Kronzon I, et al. Discrete atherosclerotic coronary artery aneurysms: a study of 20 patients. J Am Coll Cardiol 1990;15:279-82.

8 Villines TC, Avedissian LS, Elgin EE, et al. Diffuse nonatherosclerotic coronary aneurysms. Cardiol Rev 2005;13:309-11.

9 Ouali S, Kacem S, Ben Fradj F, et al. Takayasu arteritis with coronary aneurysms causing acute myocardial infarction in a young man. Tex Heart Inst J 2011;38:183-6.

10 Núñez-Gil IJ, Alberca PM, Gonzalo N, et al. Giant coronary aneurysm culprit of an acute coronary syndrome. Rev Port Cardiol 2018;37:203.e1-203.e5.

11 Yanık A, Arslan U, Akçay M, et al. Giant Coronary Artery Aneurysm Causing Acute Anterior Myocardial Infarction. Case Rep Med 2016;2016:1-2.

12 Sugahara Y, Ishii M, Muta H, et al. Warfarin therapy for giant aneurysm prevents myocardial infarction in Kawasaki disease. Pediatr Cardiol 2008;29:398-401.

13 Suda K, Kudo Y, Higaki T, et al. Multicenter and retrospective case study of warfarin and aspirin combination therapy in patients with giant coronary aneurysms caused by Kawasaki disease. Circ J 2009;73:1319-23.

14 Whittaker A, Wilkinson JR. Incidental finding of a giant coronary artery aneurysm of the left anterior descending artery. Heart 2013;99:1138-9.

15 Sobczak S, Jegier B, Stefanczyk L, et al. Giant aneurysm of the right coronary artery and magnetic resonance coronary angiography. Ann Saudi Med 2014;34:346-50.

16 Saleh WK, Aljabbari 0, Reardon MJ. Case Report: A Rare Case of a Giant Right Coronary Artery Aneurysm. Methodist Debakey Cardiovasc J 2015;11:135-6.

17 Choi KM, Kim RJ, Gubernikoff G, et al. Transmural extent of acute myocardial infarction predicts long-term improvement in contractile function. Circulation 2001:104:1101-7.

18 Kitagawa K, Sakuma H, Hirano T, et al. Acute myocardial infarction: myocardial viability assessment in patients early thereafter comparison of contrast-enhanced MR imaging with resting (201)TI SPECT. Single photon emission computed tomography. Radiology 2003;226:138-44.

Copyright 2019 BMJ Publishing Group. All rights reserved. For permission to reuse any of this content visit

https://www.bmj.com/company/products-services/rights-and-licensing/permissions/

BMJ Case Report Fellows may re-use this article for personal use and teaching without any further permission.

Become a Fellow of BMJ Case Reports today and you can:

- Submit as many cases as you like

- Enjoy fast sympathetic peer review and rapid publication of accepted articles

- Access all the published articles

Re-use any of the published material for personal use and teaching without further permission

Customer Service

If you have any further queries about your subscription, please contact our customer services team on +44 (0) 2071111105 or via email at support@bmj.com.

Visit casereports.bmj.com for more articles like this and to become a Fellow 